\title{
REM Latency in Psychotically Depressed Adolescents
}

\author{
Michael W. Naylor, Benjamin N. Shain, and James E. Shipley
}

\section{Introduction}

Major depression in adults is accompanied by characteristic polysomnographic abnormalities, including shorter latency to rapid eye movement (REM) sleep, less slow wave sleep, impaired sleep continuity, greater REM activity (especially in the first REM period), and elevated REM density compared with nondepressed agematched controls (Kupfer et al. 1978). Thase et al. (1986) demonstrated that REM latency may be dependent upon depressive subtype. In their study, psychotically depressed subjects had significantly shorter REM latencies than depressed patients without psychotic features. Sleep onset REM periods were frequently seen in their population of psychotically depressed adults.

Studies of REM latency in depressed adolescents have been inconclusive. Goetz et al. (1987) and Appelboom-Fondu et al. (1988) failed to find short REM latency in depressed adolescents compared with normal controls. In conrast, Lahmeyer et al. (1983) and Emslie et al. (1988) found that depressed adolescents had shorter PFM latencies than age-matched normal controls. None of these studies compared REM sleep in psychotically and nonpsychotically depressed adolescents. We undertook this preliminary study to examine the relationship between

From the University of Micnigan, Department of Psychiatry, Ciild and Adolescent Psychiatric Hospital (M.W.N., B.N.S.) and the Sleep Diagnostic and Research Program (M.W.N., J.E.S.)

Address reprint icquests to Michael W. Naylor, M.D., Department of Psychiatry, Box 0706, 1500 E. Medical Center Drive, Ann Ateor, MI 40i09-0706.

Received November 30, 1989; revised February 3, 1990. subtype of depression (rsychotic versus nonpsychotic) and REM latency in adolescents. We hypothesized that psychotically depressed adolescents would have shorter REM latencies than depressed adolescents without psychosis.

\section{Methods}

The subjects were 12 unipolar depressed adolescents admitted to the University of Michigan Adolescent Psychiatry Unit. Informed consent was obtained. The sample included 5 boys and 7 girls ages $13.4-17.0$ years $($ mean $=15.6$ years). Diagnoses were made according to Research Diagnostic Criteria (Spitzer et al. 1973) based on information obtained from a semistructured interview, the Schedule for Affective Disorders and Schizophrenia (Endicott and Spitzer 1978). Depression severity was measured with the Hamilton Rating Scale for Depression (HRSD) (Hamilton 1960) and the Chiluren's Depression Rating Scale-Revised (CDRS-R) (Poznanski et al. 1984). All patients were observed psychotropic medication free in the hospital for 2 weeks prior to the study. Only those who remained depressed throughout the observation period were included in the study. Patients were studied polysornnugraphically from their own beds for 2 nights using an electroencephalogram (EEG) sleep telemetry system. The studies were performed as described previously (Grunhaus et al. 1988). All polygraph records were scored visually on the basis of 1-min epochs according to Rechtschaffen-Kales et al. (1968) criteria by experienced technicians blind to patient diag- 
Table 1. Sleep Variables in Depressed Adolescents with and Without Psychotic Features (Mean \pm SD)

\begin{tabular}{lccc}
\hline & $\begin{array}{c}\text { Psychotic } \\
(\mathrm{n}=5)\end{array}$ & $\begin{array}{c}\text { Nonpsychotic } \\
(\mathrm{n}=7)\end{array}$ & $p<\mathbf{0}^{\mathbf{2}}$ \\
\hline Sleep continuity & & & \\
Sleep latency & $46.8 \pm 17.7$ & $39.2 \pm 14.1$ & NS \\
WASO & $11.3 \pm 19.2$ & $1.8 \pm 1.8$ & NS \\
ALT & $4.7 \pm 9.4$ & $1.8 \pm 1.6$ & NS \\
Arousals & $0.8 \pm 1.0$ & $1.4 \pm 1.5$ & NS \\
Sleep efficiency & $84.1 \pm 6.6$ & $89.2 \pm 3.4$ & \\
Sleep stages & & & NS \\
Stage 1 (\%) & $9.5 \pm 3.1$ & $6.8 \pm 4.4$ & NS \\
Stage 2(\%) & $51.4 \pm 3.3$ & $50.0 \pm 4.7$ & NS \\
Delta sletp (\%) & $23.3 \pm 4.1$ & $27.1 \pm 9.9$ & \\
REM (\%) & $15.9 \pm 2.5$ & $15.4 \pm 4.2$ & NS \\
REM variables & & & NS \\
REM latency & $70.9 \pm 11.5$ & $122.4 \pm 33.2$ & NS \\
REM activity & $57.4 \pm 18.7$ & $58.8 \pm 29.5$ & NS \\
Density REM 1 & $0.7 \pm 0.3$ & $0.6 \pm 0.2$ & \\
Activity REM 1 & $6.3 \pm 2.5$ & $8.9 \pm 6.4$ & \\
\hline
\end{tabular}

Mann-Whitrey U-test.

WASO $=$ wakefulness after sleep onset; ALT $=$ awake last $\mathbf{z} \mathrm{hr}$.

nosis. Sleep variables were averaged over the 2 nights of the study and analyzed. Data for REM latency (measured from sleep onset to the beginning of the first REM period of at least $3 \mathrm{~min}$ duration) were further anaiyzed to assess the presence of a first night effect between nights and between groups to determine whether the findings were similar when each night was considered separately.

Group comparisons between psychotic and nonpsychotic depressed adolescents were made using a Mann-Whitney U-test. A two-tailed Fisher's exact test was used to examine the distribution of patients into psychotic versus nonpsychotic and short versus long REM latency groups. We used Pearson's product-moment correlation coefficient to study the relationship between REM latency and severity of depression.

\section{Results}

Psychoticalíy depresęd adolescents did not differ from nonpsyclutic pationts in terms of age $(15.9 \pm 0.8$ versus $15.3 \pm 1.5$ years; $Z=$
-0.49 , NS). As measured by the HRSD, psychotically depressed adolescents were more severely depressed $(23.6 \pm 5.0$ versus $16.6 \pm$ $4.3 ; Z=-2.04 ; p<0.05)$. The CDRS showed $a$ trend in the same direction (73.6 \pm 13.4 versus $55.7 \pm 12.4 ; Z=-1.87, p<0.07)$.

Psychotically depressed adolescents had a significantly shorter REM latency as a group $(70.9 \pm 11.5$ versus $122.4 \pm 33.2 \mathrm{~min} ; Z=$ $-2.36 ; p<0.02$ ) (Table $i)$. We found no significani correlation between REM latency and severity of depression as measured by the CDRS$R$ or HRSD. When the patients were divided into short versus long REM latency groups basad on a natural split in the data (Figure 1), all psychotically depressed patients fell into the short REM latency group, a ristribution that was statistically significant (Fisher's exact test; $p<$ 0.03).

There was no significant difference in REM latency between night 1 and night 2 within either patient group (Mann-Whitney U-test, NS). Analyzing between-group differences by individual nights, REM latency was sigrificantly lower on the second night in psychocically depressed ad- 


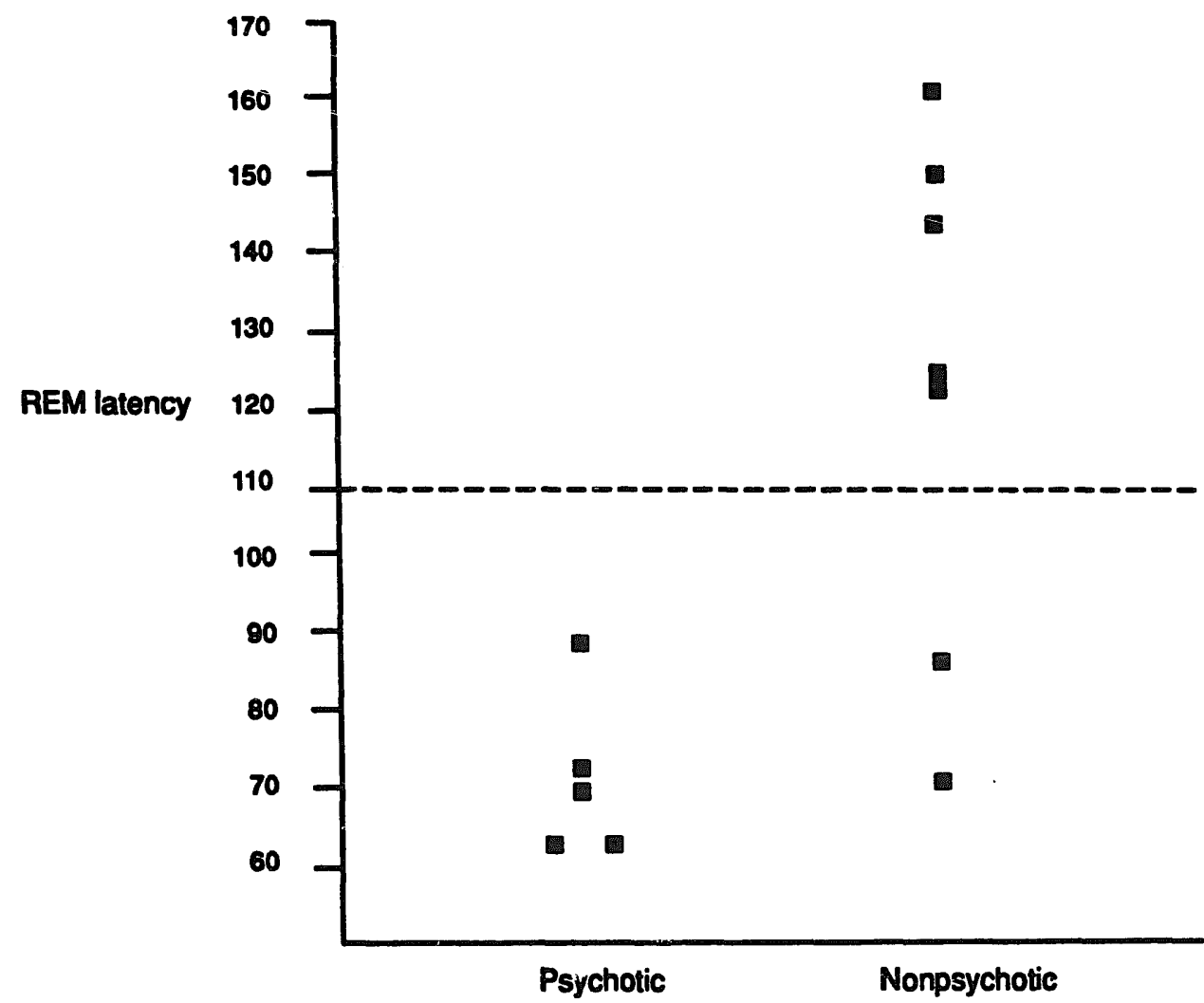

Figure 1. REM sleep latency distribution and depressive subtype

olescents $(72.0 \pm 19.7$ versus $123.0 \pm 40.2$ $\min ; Z=-2.20 ; p<0.03)$. The difference approached significance for the first night (69.8 \pm 19.7 versus $121.7 \pm 40.9 \mathrm{~min} ; Z=-1.87$; $p<0.07$ ).

\section{Discussion}

Our results show that depressed adoiescents with psychosis have a shorter REM latency than those without psychosis. We conclude that the development of shortened REM latency in depressed patients is. influenced by the subtype of depression. The lack of corralation between severity of depression and REM latency must be viewed with caution due to the small sample size and the discontinuous nature of the REM latency data.

These results may shed some light or: the previously mentioned discrepancies between
REM latency findings in depressed adolescents. Studies involving predominantly outpatients have found no REM latency differences between depressed adolescents and normal controls (Goetz et al. 1987; Appelboom-Fondu et al. 1988), whereas those involving inpatients (Emslie et al. 1988) or both inpatients and outpatients (Lahmeyer et al. 1983) have found shortened REM latencies. Inpatient status presumes a level of severity not seen in depressed adolescents treated as outpatients. Depressive subtype may be one mediator of severity. Psycirotically depressed adolescents are unlikely to be managed on an outpatient basis.

Seraral aspects of our study deserve further comment. First, this is a preliminary report and needs to be replicated in a larger sample. Second, we averaged the data across the first and second nights. Whereas the literature points to a clear firsi night effect of the laboratory on sleep 
in normal subjects, including prolongation of REM latency (Agnew et al. 1966), we found no difference between night 1 and night 2 REM latency values in either group of depressed adolescents. This phenomenon was previously described in adults hospitalized for major depression (Ansseau et al. 1985). Third, we did not have a normal control group. The use of a nonpsychotically depressed contro group as opposed to normal subjects, however, is a more rigorous test of our hypothesis that psychotic depression is accompanied by shortened REM latency.

Further research is needed to identify factors that may account for the shortened REM latency observed in psychotically depressed adoles. cents.

\section{References}

Agnew HW, Webb WB, Williamis RL (1966): The first night effect: An EEG study of sleep. Psychophysiology 2:263-266.

Ansséau M, Kupfer DJ, Reynolds CF, Coble PA (1985): "Paradoxical" shortening of REM latency on first recording night in major depressive disorder: Clinical and polysomnographic correlates. biol Psychiatry 20:135-145.

Appelboom-Fondu J, Kerkhofs M, Mendlewicz J (1988): Depression in adolescents and young adults-Polysomnographic and neuroendocrine aspects. J Affective Disord 14:35-40.

Emslie GJ, Rush AJ, Weinberg WA, Rintelmann J, Roffwarg HP (1988): Polysomnographic findings in depressed children and adolescents. Sleep Res 17:121.

Endicott J, Spitzer RL (1978): A diagnostic interview. Arch Geri Psychiatry 35:837-844.

Goetz RR, Puig-Antich J, Ryan N, et al (1987): Electroencephalographic sleep of adolescents with major depression and normal controls. Arch Gen Psychiatry 44:61-68.

Grunhaus L, Tiongco D, Pande A, et al (1988): Monitoring of antidepressant response to ECT with polysomxographic recordings and the dexamethasone suppression test. Psychiatry Res 24:177185.

Hamilton M (1960): A rating scale for depression. J Neurol Neurosurg Psychiatry 23:56-62.

Kupfer DI, Foster FG, Coble P, et al (1978): The application of EEG sleep for the differential diagnosis of affective disorders. Am $J$ Psychiatry 135:69-74.

Lahmeyer HW, Poznanski EO, Bellur SN (1983): EEG sleep in depressed adolescents. Am J Psy. chiatry 140:1150-1153.

Poznanski EO, Grossman JA, Buchsbaum Y, et al (1984): Preliminary studies of the reliability and validity of the Children's Depression Rating Scale. J Am Acad Child Psychiatry 23:191-197.

Rechtschaffen A, Kales A, Berger RJ, et al (1968): A manual of standardized terminology, techniques, and scoring system for sleep stages of human subjects. Washington, DC: Public Health Service; U.S. Government Printing Office.

Spitzer RL, Endicott J, Robbins E (1978): Research diagnostic criteria. Arch Gen Psychiatry 35:773782.

Thase ME, Kupfer DJ, Ulrich RF (1986): Electroencephalographic sleep in psychotic depression: A valid subtype? Arch Gers Psychiatry 43:886$-893$. 